\title{
Determination of the chemical composition distribution of copolymers of styrene and butadiene by gradient polymer elution chromatography
}

\author{
Citation for published version (APA): \\ Cools, P. J. C. H., Maesen, F., Klumperman, B., Herk, van, A. M., \& German, A. L. (1996). Determination of the \\ chemical composition distribution of copolymers of styrene and butadiene by gradient polymer elution \\ chromatography. Journal of Chromatography, A, 736(1-2), 125-130. https://doi.org/10.1016/0021- \\ 9673(95)01369-5
}

DOI:

10.1016/0021-9673(95)01369-5

Document status and date:

Published: 01/01/1996

Document Version:

Publisher's PDF, also known as Version of Record (includes final page, issue and volume numbers)

\section{Please check the document version of this publication:}

- A submitted manuscript is the version of the article upon submission and before peer-review. There can be important differences between the submitted version and the official published version of record. People interested in the research are advised to contact the author for the final version of the publication, or visit the DOI to the publisher's website.

- The final author version and the galley proof are versions of the publication after peer review.

- The final published version features the final layout of the paper including the volume, issue and page numbers.

Link to publication

\footnotetext{
General rights

- You may freely distribute the URL identifying the publication in the public portal. follow below link for the End User Agreement:

www.tue.nl/taverne

\section{Take down policy}

If you believe that this document breaches copyright please contact us at:

openaccess@tue.nl

providing details and we will investigate your claim.
}

Copyright and moral rights for the publications made accessible in the public portal are retained by the authors and/or other copyright owners and it is a condition of accessing publications that users recognise and abide by the legal requirements associated with these rights.

- Users may download and print one copy of any publication from the public portal for the purpose of private study or research.

- You may not further distribute the material or use it for any profit-making activity or commercial gain

If the publication is distributed under the terms of Article $25 \mathrm{fa}$ of the Dutch Copyright Act, indicated by the "Taverne" license above, please 


\title{
Determination of the chemical composition distribution of copolymers of styrene and butadiene by gradient polymer elution chromatography
}

\author{
P.J.C.H. Cools, F. Maesen, B. Klumperman*, A.M. van Herk, A.L. German \\ Laboratory of Polymer Chemistry, Eindhoven University of Technology, P.O. Box 513, 5600 MB Eindhoven, Netherlands
}

Received 16 August 1995; revised 20 December 1995; accepted 20 December 1995

\begin{abstract}
In order to determine the chemical composition distribution (CCD) of styrene-butadiene copolymers, gradient polymer elution chromatography has been performed. The separation is mainly based on differences in solubility among the copolymer molecules with different chemical composition. The solubility of a copolymer is dependent on the following parameters: temperature, type of solvent/non-solvent mixture, molecular mass of the polymer and the chemical composition of the polymer. The resolution of the gradient polymer elution chromatographic separation and the molecular mass dependency are influenced by the solvent/non-solvent combination. In order to obtain a reliable separation according to chemical composition, the differences in solubility must be sufficiently high and the molecular mass dependence must be negligible. In order to separate styrene-butadiene copolymers, synthesized by emulsion polymerization, a tetrahydrofuranacetonitrile gradient was used. After calibration of the chromatographic system with styrene-butadiene copolymer standards, the CCD of styrene-butadiene copolymers could be calculated.
\end{abstract}

Keywords: Gradient polymer elution chromatography; Polymers; Styrene; Butadiene; Polystyrene-butadiene

\section{Introduction}

Over the last few years, polymer characterization has become more important. New techniques have been developed in order to determine the chemical composition of a copolymer, Different techniques can be used in order to characterize a copolymer. Size-exclusion chromatography (SEC) can be used to obtain the molecular mass distribution (MMD). ${ }^{1} \mathrm{H}$ NMR can be used to determine the average mole fraction $\left(\bar{F}_{1}, \bar{F}_{2}\right)$ of monomeric units in a copolymer.

However, during a copolymerization a chemical

${ }^{*}$ Corresponding author. composition distribution (CCD) is formed due to statistical broadening and composition drift (batch copolymerization). Depending on the monomer combination, process conditions and process strategy, a broad CCD may occur. Together with the $M M D$, the CCD determines the properties of the copolymer. Thus the knowledge of the $\mathrm{CCD}$ of copolymers is of crucial importance.

Gradient polymer elution chromatography (GPEC; in some countries GPEC is a registered trademark of Waters [1-3]) is a high-performance liquid chromatography (HPLC) method that is capable of separating polymer molecules according to chemical composition. The separation mechanism of GPEC is 
mainly based on the differences in solubility among copolymers with different chemical composition.

In the literature, gradient HPLC is often called high-performance precipitation liquid chromatography (HPPLC) $[4,5]$ or liquid adsorption chromatography (LAC) [6,7]. HPPLC emphasizes solely on the precipitation mechanism and LAC focuses solely on the adsorption mechanism. In gradient HPLC, precipitation and adsorption can occur. Because HPPLC and LAC only describe part of the mechanism, a more general name for the technique was introduced: gradient polymer elution chromatography, which does not a priori infer a specific separation mechanism [2,3].

At the beginning of the GPEC separation process, the chromatographic eluent is a non-solvent. The polymer sample is injected in the non-solvent and will precipitate on the column. During the GPEC separation, the solvent composition is changing gradually in time from non-solvent to a good solvent. According to the chemical composition and molecular mass of the copolymers, the polymers will redissolve in a certain solvent composition. Therefore, polymers with different chemical composition will elute at different retention times and separation occurs.

The solubility of a polymer depends upon the following parameters: type and molecular mass of the polymer, solvent/non-solvent combination and the temperature. During a GPEC separation, the temperature is kept constant.

The solvent/non-solvent combination is an important parameter in GPEC. By choosing the right solvent/non-solvent combination a successful separation can be achieved. Previous research has shown that in most solvent/non-solvent combinations the molecular mass dependence is negligible above 100 $\mathrm{kDa}$. Therefore, polymers obtained by emulsion polymerization, which tend to have high molecular masses, can generally be separated by GPEC exclusively according to chemical composition.

Separation on the basis of solubility is not the only separation mechanism operative during a GPEC separation. Adsorption of the polymer molecules on the stationary phase and exclusion of the polymer molecules from the pores can also occur. Adsorption will cause an extra retention of the polymer molecules. Exclusion causes the polymer molecules to accelerate relative to the eluent moving through the column. Consequently, both effects, adsorption and exclusion, may have a considerable effect on the separation [3].

GPEC can be performed in order to determine the chemical composition of a polymer blend. The method can also be used to determine the CCD of a copolymer.

The CCD of a copolymer can be calculated by using a calibration curve, which can be obtained by measuring the GPEC retention times of homogeneous copolymers with well-defined chemical compositions.

\section{Experimental}

In order to determine the CCD of a copolymer, the proper GPEC conditions have to be found. The GPEC conditions can be found by looking at the solubility behaviour of the relevant homopolymers (polystyrene and polybutadiene) in different solvent/ non-solvent combinations. The solubility behaviour of a polymer can be studied by turbidity measurements.

By determining the cloud points of the homopolymer standards with different molecular masses different solvent/non-solvent combinations can be tested. The cloud point composition (CPC) is determined by titration of a polymer solution (concentration $1.6 \mathrm{mg} / \mathrm{ml}$ ) with a non-solvent. The CPC is defined as the fraction of solvent in the solvent/ non-solvent mixture at the onset of turbidity. In order to obtain the turbidity curve, the CPCs of different polystyrene (PS) standards and polybutadiene (PB) standards were determined (the number indicates the molecular mass in Da): PS 500, PS 2500, PS 18000 , PS 102000 , PS $2.7 \times 10^{6}$, PB 900, PB 9300, PB 120000 and PB 950000 (see Table 1). The homopolymers were GPC standards from Polymer Labs. and Waters.

The molecular mass dependence on the cloud points and on the GPEC separation is determined.

The weight fractions styrene in the styrenebutadiene copolymer standards (Scientific Polymer Products) were 45, 23 and 5\% (determined from its refractive index). The molecular masses of the PSB 
Table 1

Cloud point compositions (CPC) of PS and PB standards in THF-ACN

\begin{tabular}{lcl}
\hline & $\begin{array}{l}\text { Molecular mass } \\
(\mathrm{kDa})\end{array}$ & $\begin{array}{l}\text { CPC } \\
\text { (vol. \% THF in ACN) }\end{array}$ \\
\hline PS 500 & 0.5 & - \\
PS 2500 & 2.5 & - \\
PS 18 000 & 18 & 29.0 \\
PS 102000 & 102 & 42.0 \\
PS 2.7 $\times 10^{6}$ & 2700 & 48.2 \\
PB 900 & 9 & - \\
PB 9300 & 9.3 & 61.4 \\
PB 120 000 & 120 & 73.7 \\
PS 950 000 & 950 & 76.0 \\
\hline
\end{tabular}

The concentrations of the solutions are approx. $1 \mathrm{mg} / \mathrm{ml}$.

standards are 350,300 and $400 \mathrm{kDa}$, respectively, as determined by SEC.

The styrene-butadiene copolymer sample is a random copolymer obtained by emulsion polymerization. The average styrene content, $33 \mathrm{~mol} \%$, was determined by refractive index, the average molecular mass is about $300 \mathrm{kDa}$ (as determined by SEC).

The molecular mass dependence is negligible above $100 \mathrm{kDa}$ in the system tetrahydrofuran (THF)-acetonitrile (ACN) for both PS and PB (see Fig. 1). The difference between CPC of the homopolymer standards PS 100000 en PB 100000 is about $30 \%$ THF. So the system THF-ACN can be

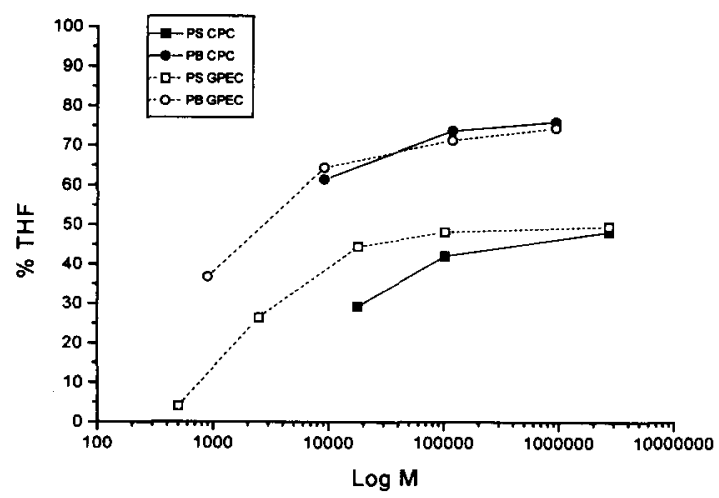

Fig. 1. Molecular mass $(M)$ dependencies of PS and PB in THF-ACN of the cloud point titrations (continuous line) and of the GPEC separation (broken lines). (a) Cloud point titrations of PS standards; ( $\square$ ) GPEC of PS standards; (O) cloud point titrations of PB standards; (O) GPEC of PB standards. used in order to separate styrene-butadiene copolymers.

\subsection{Apparatus}

The experiments were performed with a WISP (Waters Intelligent Sample Processor) injector, a Waters $600 \mathrm{E}$ gradient controller with pump, a Waters $484 \mathrm{UV}$ detector and an evaporative light scattering detection (ELSD) system (ACS Model 750/14). The column used for the GPEC separation was a $7.5 \mathrm{~cm}$ NovaPak $\mathrm{C}_{18}\left(35^{\circ} \mathrm{C}\right)$. The wavelength of the UV detector was set at $260 \mathrm{~nm}$. The linear gradient used was changing from 35 to $70 \% \mathrm{THF}$ in $35 \mathrm{~min}$ (gradient slope $1 \% / \mathrm{min}$ ). The injection volume was $25 \mu \mathrm{l}$. The flow-rate was $1.0 \mathrm{ml} / \mathrm{min}$.

THF (Westburg, HPLC grade) was used as solvent. ACN (Biosolve, HPLC grade) was used as non-solvent.

\subsection{GPEC technique}

The PS standards and the PB standards were dissolved in THF $(1 \mathrm{mg} / \mathrm{ml})$. At the beginning of the gradient, the eluent was a non-solvent. The polymers (in solution) were injected into the non-solvent and precipitated on the column material, because of the poor solvent conditions. When the gradient was performed, the polymer molecules redissolved in a specific solvent composition and eventually eluted from the column, leading to separation according to their chemical composition.

\subsection{Chemical composition distribution}

In order to calculate the CCD, the GPEC behaviour of the homopolymers of each of the two monomers was studied. The difference between the retention times of the two homopolymers must be sufficiently high, in order to obtain a high resolution. Also, the molecular mass dependence of the homopolymers on the solubility was studied.

With well-defined homogeneous PSB copolymers a calibration curve was determined, in order to obtain a relation between the chemical composition and the retention time (similar to SEC molecular mass vs. retention time).

With the calibration curve, the CCD of a co- 
polymer was calculated in the same way as a MMD can be calculated (see Fig. 4). The chromatogram was cut in slices of the same width. For each slice the chemical composition was determined using the calibration curve. The height (in the chromatogram) of each slice $\left(h_{i}\right)$ is a measure of the concentration. By calculating the weight fraction of each slice $\left(w_{i}\right)$, the chemical composition distribution could be calculated. For the CCD calctlation, the ELSD signal was used.

\section{Results and discussion}

In order to determine the CCD of styrenebutadiene copolymers, a THF-ACN gradient was used. In Fig. 1 the molecular mass dependence of PS and PB on the CPC and on the GPEC separation is shown. The retention times of the GPEC separations are translated into percentage THF (\% THF). The chromatograms of the GPEC separation of the homopolymers are shown in Fig. 2 and Fig. 3.

Fig. 1 shows that the molecular mass dependence of PS decreases in the GPEC; separation in comparison to the molecular mass dependence on the CPC as determined by turbidimetric titration. The decrease of the molecular mass dependence of the PS in the GPEC experiments is most probably due to



Fig. 2. GPEC chromatogram of polystyrene standards with different molecular masses $(0.5,2.5,18,100$ and $2700 \mathrm{kDa}$; $k=10^{3}$ ).

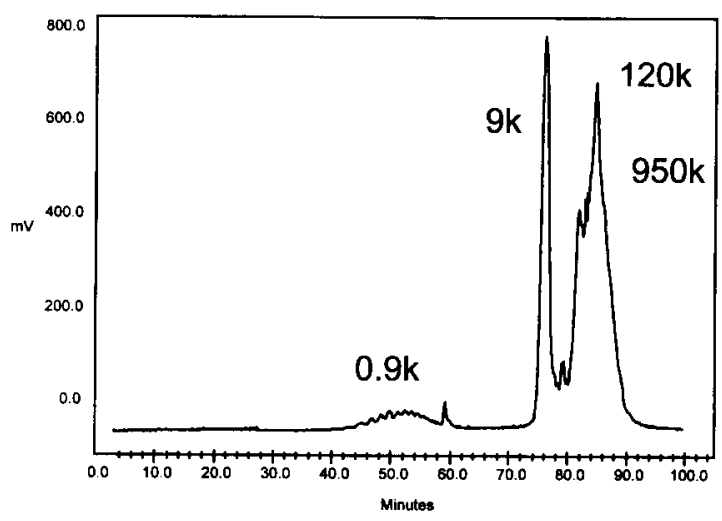

Fig. 3. GPEC chromatogram of polybutadiene standards with different molecular masses $\left(0.9,9,120\right.$ and $\left.950 \mathrm{kDa} ; \mathrm{k}=10^{3}\right)$.

adsorption effects. The dependence of the molecular mass on the GPEC separation is negligible for PS and PB above molecular masses of $100 \mathrm{kDa}$. Polymers synthesized by emulsion copolymerization generally have molecular masses above $100 \mathrm{kDa}$; consequently, the gradient AC-THF can be applied in order to separate styrene-butadiene emulsion copolymers solely on chemical composition.

The difference between the cloud points of highmolecular-mass polystyrene and high-molecularmass polybutadiene in the system THF-ACN is sufficiently high to obtain a separation according to chemical composition (see Fig. 1).

The CCD of the PSB sample has been calculated from the chromatogram according to the method described schematically in Fig. 4.

A linear calibration curve ( $F_{s}$ versus \%THF) was found (intercept $=328$, slope $=-4.42$ ), as can be seen
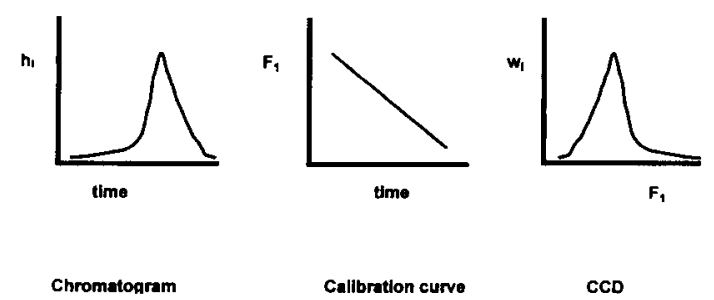

CCD

Fig. 4. Determination of the CCD of a copolymer. 


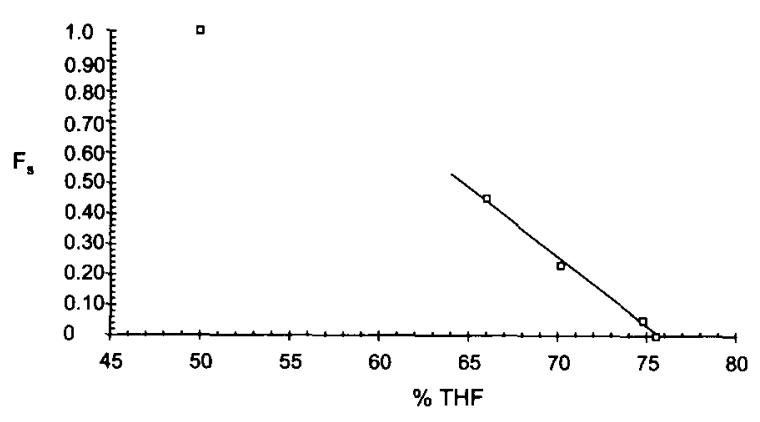

Fig. 5. Calibration curve for GPEC separation of styrenebutadiene copolymers; linear gradient ACN-THF, NovaPak $\mathrm{C}_{18}$, flow-rate $1.0 \mathrm{ml} / \mathrm{min}$; PSB standards with $F_{\mathrm{s}}$ values $0.05,0.23$ and 0.45 , and the homopolymers $\left(F_{\mathrm{s}} 1.0\right.$ and 0.0$)$.

in Fig. 5. The calibration curve is only valid for low styrene contents $\left(F_{\mathrm{s}} \leq 0.50\right)$, because no styrenebutadiene copolymer standards with high styrene content were available.

A GPEC chromatogram of the styrene-butadiene copolymer is presented in Fig. 6. The chromatogram indicates that beside a copolymer also homopolymer is present in the copolymer sample. Due to composition drift, polystyrene has been formed, probably at the end of the reaction. The CCD of the PSB sample is plotted in Fig. 7.

The ELSD response $\left(h_{i}\right)$ is assumed to be independent of the copolymer composition. Any possible dependence of the response on copolymer composition may result in a slight correction of the CCD.

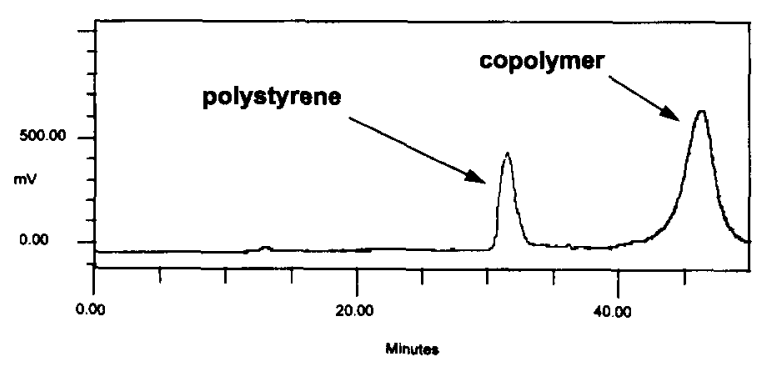

Fig. 6. GPEC chromatogram of styrene-butadiene copolymer; ELSD, linear gradient ACN-THF, NovaPak $\mathrm{C}_{18}$, flow-rate 1.0 $\mathrm{ml} / \mathrm{min}$.

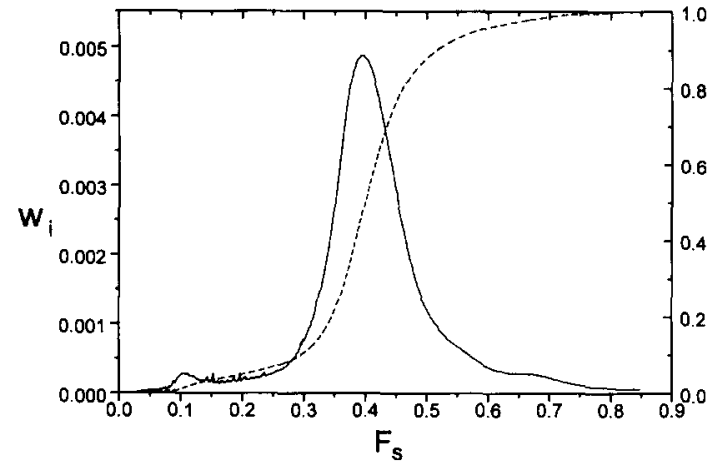

Fig. 7. Chemical composition distribution of a styrene-butadiene copolymer.

\section{Conclusions}

For each type of copolymer a new solvent/nonsolvent combination has to be found in order to obtain a successful separation according to chemical composition. In the system THF-ACN the molecular mass dependence on the GPEC separation of styrene-butadiene copolymers, with sufficiently high molecular mass (above $100 \mathrm{kDa}$ ), is negligible. In other systems, the molecular mass of the polymer may disturb the separation according to chemical composition. Hence, similar to SEC separations, the separations performed by GPEC should be interpreted with great care. The dependence of GPEC separations on copolymer molecular mass in general requires further study.

In case of the separation of styrene-butadiene copolymers, a suitable solvent/non-solvent combination was found. With this solvent/non-solvent combination (THF-ACN), reproducible GPEC chromatograms of styrene-butadiene copolymers were obtained.

GPEC can be used to determine the copolymer CCDs, which are of great value in predicting and understanding copolymer product properties. Also information about the kinetics of the polymerization can be obtained.

GPEC appears to be a powerful tool in the characterization of copolymers according to chemical composition. 


\section{References}

[1] W. Staal, P.J.C.H. Cools, A.M. van Herk and A.L. German, J. Liq. Chromatogr, 17 (1994) 3191.

[2] P.J.C.H. Cools, A.M. van Herk, W. Staal and A.L. German, J. Liq. Chromatogr., 17 (1994) 3133.

[3] H.J.A. Philipsen, B. Klumperman and A.L. German. J. Chromatogr. A, 727 (1996) 13.
[4] G. Glöckner, Gradient HPLC of Copolymers and Chromatographic Cross Fractionation, Springer, Berlin, 1991.

[5] S. Mori, H. Taziri, J. Liq. Chromatogr., 17 (1994) 3055.

[6] S. Mori, Anal. Sci., 4 (1988) 365.

[7] S. Mori, Anal. Chem., 60 (1988) 1125. 